\title{
Professional Associations AND Deflection TActics: A Theory AND EXPLORATORY ANALYSIS
}

Michael f. Sheridan, Michael Hartmann, and Erik fonisz

Michael Sheridan (sheridam@newpaltz.edu) is an Associate Professor at the State University of New York at New Paltz, School of Business, 1 Hawk Dr., New Paltz, NY 12561. Michael Hartmann (michael.hartmann@hs-augsburg.de) is on the Faculty of Business at the University of Applied Sciences, Augsburg, Germany. Erik Jonisz received his MBA from the State University of New York at New Paltz. All correspondence regarding this manuscript should be addressed to Michael Sheridan.

Please note that the authors did not receive any financial support for this research, nor do any competing interests exist. The manuscript is an original work and has not been published previously. Each author has read and approved the manuscript and meet the stated criteria for authorship.

\begin{abstract}
This study introduces deflection as a new form of institutional maintenance that enables established actors in an institutional field to mitigate negative impacts of legitimacy judgments. Deflection
\end{abstract}




\section{The BRC Academy Journal of Business Vol. 7, No. 1}

may be considered to be a special form of buffering that can appear when the legitimacy judgment and the sentencing decision are discrete events. Specifically, this study presents two propositions to explore the ability of actors to draw upon the influence of their counterparts to engage in the deflection strategy which, in turn, can influence the stability of the population in an institutional field. 897 decisions of the appellant court of the National Organic Program from 2009 until 2012 were analyzed to assess the impact of field level characteristics (trade association membership) and organizational attributes (country of origin, subsidiary status, and revenue) upon the success of deflection strategies. When the characteristics of both the firm facing the court's decision as well as their certifying agent were considered, it was found that the professional association membership status of the certifying agent significantly related to the outcomes of the court's ruling.

Keywords: institutional theory; institutional maintenance; institutional work; confrontation; deflection; field level dynamics; professional associations; organic food industry; logistic regression

Data Availability: The authors used publicly-available data.

DOI: http://dx.doi.org/10.15239/j.brcacadjb.2017.07.01.ja02

\section{INTRODUCTION}

Lately organizational scholars have returned their focus to intentionality and agency with new found emphasis on topics such as the creation and disruption of institutions (Lawrence, Suddaby, \& Leca, 2011; Scott, 2014) and the influence of corporations on regulatory agencies (Barley, 2010). However, with the notable exceptions of Hirsch and Bermiss (2009) and Trank and Washington (2009), the maintenance of institutions, another intentional process, has received less attention. Another topic receiving little empirical consideration has been the role of professional associations in institutional fields (Greenwood, Hinings, \& Suddaby, 2002), although many authors have acknowledged professional associations 
as influential actors (Barley, 2010; DiMaggio \& Powell, 1983; King \& Lenox, 2000; Suddaby \& Viale, 2011). In order to better understand the role of professional associations and institutional maintenance, literature concerning strategic responses to institutional pressures (Meyer \& Rowan, 1977; Oliver, 1991) and institutional work (Lawrence \& Suddaby, 2006) were examined in order to introduce deflection, a new tactic of institutional maintenance. Deflection preserves existing institutions as it aims to protect organizations from an impending legitimacy challenge by ensuring the continuity of membership in an institutional field and may be understood as a special form of buffering (Meyer \& Rowan, 1977) that occurs when the legitimacy judgment and the sentencing decision occur separately.

The organic food industry was used as an empirical context to explore the role of a professional associations' deflection strategies and how they protect their member organizations from legitimacy challenges. Since the organic industry relies upon third party certifiers to verify the operations of these firms, the impact of membership status of the certifying agency upon the outcome of the deflection tactic was also explored in this study.

This research makes at least three contributions to the literature. First, it recognizes deflection as a new form of institutional maintenance, a strategy intended to mitigate the effects of an impending legitimacy challenge. Deflection strategies represent a special case of buffering, as they are most likely to occur when the legitimacy challenge and judgment are discrete events. Second, the study furthers an understanding of the maintenance tactics of professional associations by highlighting the impact of professional associations upon deflection strategies. Finally, by considering the characteristics of an important partner firm, the paper incorporates an additional dynamic to institutional studies. 


\section{LiterATURE REVIEW}

\section{Institutional Work}

This research was developed on the concept that institutional work is the "purposive action of individuals and organizations aimed at creating, maintaining, and disrupting institutions" (Lawrence \& Suddaby, 2006, p. 125). While the literature concerning the creative and disruptive elements of institutional work is well-established (Scott, 2014), maintenance efforts have only recently begun to receive attention and some argue that understanding the dynamics of institutional maintenance may be more important to the understanding of institutions than the mechanisms of their creation (Lawrence \& Suddaby, 2006). More broadly, the focus on maintenance may indicate a shift in the scholarship from the perspective that institutional fields are self-maintaining (c.f. Hannan \& Freeman, 1984) towards a view that considers organizations to be destined for entropy (Scott, 2014; Zucker, 1988). Yet, these competing views may be reconciled if one recognizes that once institutional logic is established, institutions require maintenance only when disrupted. Once a disruption inevitably occurs, influential actors will engage in intentional actions to protect their status to avoid any future disruptions (Giddens, 1984; Scott, 2014; Suddaby \& Viale, 2011). It is this perspective upon which this paper draws, however, the above argument is also extended by recognizing the heretofore unidentified opportunities to engage in institutional maintenance.

Previous research identified at least six types of maintenance activities deployed by actors to ensure field stability. These include enabling, policing, deterring, valorizing/demonizing, mythologizing, and embedding/routinizing (Currie, Lockett, Finn, Martin, \& Waring, 2012; Lawrence \& Suddaby, 2006). The goal of each of these activities is to buttress, restore, or reconstruct "the social mechanisms that ensure compliance" of the actors in the field (Lawrence \& Suddaby, 2006, p. 230). However, maintenance could go beyond compliance efforts by including activities 
that are less visible, such as efforts to deflect the impact of negative outcomes (Meyer \& Rowan, 1977).

Oliver's (1991) work sheds light on some of the less overt tactics available to firms facing institutional pressures. She identified five possible reactions to institutional pressures including acquiescence, compromise, avoidance, defiance and manipulation. While not universally recognized as such, they also may be considered institutional work as they require effort and intentionality (Lawrence et al., 2011). Indeed, there is considerable overlap between the Oliver typology and institutional work since the former served as a basis for Lawrence and Suddaby's (2006) influential piece on the latter. Similarly, Meyer and Rowan (1977) and others (March, Olsen, \& Christensen, 1976; Weick, 1976) recognized that decoupling the technical core of the organization could protect it from sanctions.

All of these strategies assume that the "charging" and the "sentencing" of the actor occur simultaneously, but little is written about situations in which the two events are discrete. In these situations, the period between judgment and sentencing affords an actor the opportunity to engage in a form of damage control that may be able to lessen the severity of the sentence. In other words, these actions can deflect the full impact of the negative outcome. One potential opportunity to observe the deflection strategy can occur when professional associations protect existing members from legitimacy challenges, such as potential sanctions from a regulatory agency. Since an effort such as this, if successful, would retain the status quo and protect the validity of the institution, deflection tactics could be considered as a form of institutional maintenance.

\section{Professional Associations}

An actor's position in the institutional field is likely to determine the type of institutional work performed (Currie et al., 2012) and professional associations tend to serve as agents of conformity because their members often hold powerful positions within the field (Suddaby \& Viale, 2011). 
Professional associations can be considered a "command post;" an entity that maintains order in a field by ensuring compliance with established norms and regulations (Zald \& Lounsbury, 2010). Thus, professional associations are one of the primary vehicles to maintain institutionalized activities (Granovetter, 1985; Greenwood et al., 2002).

Professional associations maintain the established institutional logic by providing support, expertise, and definitions to actors in the field. Professional associations contribute financial support to political action committees, ad hoc organizations, and other peak organizations. They also extend other forms of support to law, lobbying, and public relation firms. Professional associations also represent their industry to external actors, serving as experts during testimonials and committees, and assuming key positions in government (Barley 2010). Lastly, professional associations define elements of the institutional logic, such as pricing, safety, and quality standards, as well as the definition of causal relationships and social hierarchies (Currie et al., 2012; DiMaggio \& Powell, 1983; Lane \& Bachmann, 1997; Marchington \& Vincent, 2004).

In other words, professional associations bestow legitimacy to actors and practices in a field through these various mechanisms (Meyer \& Scott, 1983). Thus, professional associations fortify institutional practices by disseminating shared meanings and facilitating the internalization of legitimacy criteria by actors in the field (Lane \& Bachmann, 1997; Marchington \& Vincent, 2004; Ruef \& Scott, 1998). It is through this process that professional associations serve as gatekeepers to an institutional field (Lane \& Bachmann, 1997; Marchington \& Vincent, 2004; Suddaby \& Viale, 2011).

Given this gatekeeper role, it is important to recognize the reflexive nature of the relationship between trade associations and its members, as the viability of the trade associations depends on the membership of its leading organizations. Without member organization's support, professional associations could not exist. Professional associations are a "peak organization," formed as a collection of organizations that is 
reliant upon the funding of its constituents for its survival (Barley, 2010). This reciprocal dynamic between the professional association and its member organizations echoes Giddens' "structuration" theory, as member organizations simultaneously define and adhere to the social structure of the field (1990). Therefore, professional associations not only select organizations that adhere to the established criteria (Trank \& Washington, 2009), they also retain incumbent organizations that contribute to the maintenance of the institutional field. However, this role presents an opportunity for a moral hazard as well; professional associations may outwardly claim incumbent members' observance to a standard, while internally allowing for violations to continue, so long as the professional association's survival is secure (King \& Lenox, 2000).

It is this incentive to engage in deflection strategies, an attempt to preserve legitimacy in the face of disruption that suggests some interesting field-level dynamics. The paper seeks to explore these dynamics through two propositions developed to understand how effectively professional associations protect their incumbent organizations from disruptions. In other words, the propositions and subsequent analysis are meant to uncover evidence of ex post buffering tactics (Meyer \& Rowan, 1977; Thompson, 2008) that occur prior to the determination of sanctions. In this context, the technical core, represented by the incumbent members, are protected by the ceremonial adoption of the periphery. As such, this research extends the work of Meyer and Rowan (1997), Oliver (1991), and Hirsch and Bermiss (2009) by extending the notion of buffering beyond the firm's margins and into the realm of peak organizations. Moreover, this paper identifies an additional opportunity to engage in buffering by recognizing the distinction between legitimacy judgment and sentencing.

\section{Propositions}

If professional organizations sustain institutionalized practices and represent members to external actors (Greenwood et al., 2002), they would be expect to protect the status of incumbent members and to 
mitigate the effect of disruptions for their member organizations, so that they improve the likelihood of mutual survival (Suddaby \& Viale, 2011).

In this context, professional associations can mediate the regulatory environment for member organizations in a more subtle manner and potentially weaken the effect of a disruption by making promises to regulators regarding future action by the member organization (Lane \& Bachmann, 1997; Marchington \& Vincent, 2004; Tucker, 2008). Thus, when organization faces a disruption, professional associations may be able to deploy this assurance of future behavior as a deflection strategy against violations of past behavior. Although this action influences an individual organization, the phenomenon belies a broader level of influence since the strategy must be effective throughout the field in order for the professional association to maintain viability.

Proposition 1: When faced with an impending sanction, members of a professional association will be more likely to successfully deflect negative consequences than non-member organizations.

Moreover, the effectiveness of the professional association would be expected to increase as the member organization strengthens their tie to the professional association, as the co-dependency between the two organizations will deepen. Earlier research illustrated how relationships between actors can serve as a vehicle for institutional work (Empson, Cleaver, \& Allen, 2013) and this relationship possibly can also facilitate institutional maintenance. In the context of this study, the partner firm - the certifying agency - not only serves as the agent for coercive isomorphism (DiMaggio \& Powell, 1983), but it may also serve as an agent of the target firm by decreasing the severity of negative outcomes. Therefore, the potential amplification effect of the member organizations' certifying agency upon potential disruptions can also influence the outcome of deflection tactics.

Proposition 2: When faced with an impending sanction, firms who have been certified by a member of a professional association will 
be more likely to successfully deflect negative consequences than firms certified by non-member organizations.

\section{METHOD}

\section{Empirical Context}

This section briefly describes the context for the present study, with a particular focus on the basis for legitimacy in the industry. Since the topic of interest is the manner in which actors respond to legitimacy challenges when the judgment and sentence are separate, the population of this study consists of firms that appealed a violation from the National Organic Program (NOP). A brief summary of the appeals process is provided since the outcome may be associated with the professional association membership status of the offending firm and/or its certifying agency.

The organic industry provides an interesting context to explore these propositions. The industry is highly interconnected (Howard 2009), a characteristic that increases the likelihood professional associations, rather than individual organizations, will respond to institutional (Clemens \& Douglas, 2005; Goodstein, 1994; Hamel, Doz, \& Prahalad, 1989; Meyer \& Scott, 1983; Oliver, 1991). Moreover, the organic food industry features a strong moral undercurrent (Ingram \& Ingram, 2005), which makes it well-suited to analyzing legitimacy loss. Indeed, illegitimate behavior may be interpreted as sacrilege in some cases (Ashforth \& Gibbs, 1990).

\section{Description of Data}

The data were primarily drawn from three sources. The first source was a list of the appeals filed with the National Organic Program (NOP) in response to a reported violation of the USDA organic food standards. This database contained the name and address of the appellant and the associated certifying agency, as well as the outcome of the NOP ruling. This measure represents the "charge" component. The initial organic certification received by the organizations in this sample was considered 
to be a type of "social test" (Thompson, 2008) and, as such, provided the organization with license to operate. The appeals team can sustain, deny, dismiss or close the appeal without a decision or, alternatively, the case may be remanded. It is the decision of the appeals team that serves as the "sentencing" component in this study. Specifically, the act of filing an appeal with the NOP was considered as an attempt to mitigate the disruption (Ashforth \& Gibbs, 1990). When the certification is suspended or revoked, the deflection attempt either did not occur or was unsuccessful. However, when the appeals team decides to sustain or close the appeal without a decision, the legitimacy of the appellant remains intact. Unfortunately, a number of these outcomes had very few observations and thus were turned into a dichotomous dependent variable: penalized, which included revocation or suspension of license and settlements paid, and non-penalized.

Organic Trade Association membership data was drawn from the OTA website (https://www.ota.com). Information about the firms, such as age, ownership class, size, and revenue levels were gathered from Hoover's Company Records. Ten firms were eliminated from the list due to duplication of cases and because key information about revenues or firm age was missing.

The data set included both qualitative and quantitative independent variables and were analyzed with logistic regression. The categorical variables for the appellant were coded as dummy variables and included OTA membership, ownership type, industry, and country of origin. The data set also contained the ratio variables for the appellant firm, including the number of employees, age, and revenues. Categorical variables were also dummy coded for the associated certifying firm. These included the OTA membership status, sector (public or private), and the country in which the certifier was registered. The ratio variables for the certifier included age and revenues. Since the range of the values of the revenue levels for the appellant firm were much larger than those of the other data, the data were transformed the by taking the log of the revenue levels. 


\section{RESULTS}

Field (2009) lists three assumptions for testing the data for a logistic regression: independence, linearity, and multicollinearity. The independence of the variables was confirmed by ensuring that no observation occurred twice in the dataset. Linearity examines the relationship between the dependent variable's logit values. This was checked by examining if the relationship between the predictors and the log of the dependent variable was significant (Field, 2009; Hosmer Jr \& Lemeshow, 1989). Only one of the ratio variables, size of the firm, seemed to have a problem with the linearity of the logit model. This variable, however, was removed in the model estimation since it did not meet the selection criteria. The residuals of the estimated model were also analyzed according to Cook's distance (Field, 2009), and all residuals were below 0.06163, indicating that there were no individual cases which had a large effect on the model estimation. The DFBeta, which measures the exclusion of one case and its effect on the calculated parameter, was also calculated. For all of the parameters which were kept in the model, the values of the DFBeta were all less than one, indicating that no single case had a large influence on the model (Field, 2009). Moreover, an examination of the standardized residuals indicated no outliers. A sample size of at least two-hundred observations effectively eliminates the effects of non-normality, and with the final sample size of $\mathrm{n}=879$, any possible effects from non-normal data should have no impact (Hair, Black, Babin, Anderson, \& Tatham, 2006).

Multicollinearity was tested by examining the correlation matrix of the variables to check for large numbers of high correlations, i.e. values of $r>0.90$, between the independent variables. None of the pairs of variables had a correlation above 0.265 . The data were tested for multicollinearity by checking the tolerance and Variance Inflation Factor (VIF) for the data (Field, 2009; Hair et al., 2006). The values for tolerance ranged between 0.266 and .957 and the VIF scores ranged from 1.104 to 3.386, indicating low levels of possible multicollinearity. 
Preliminary data analysis included testing for missing data. Since some of the cases had some missing data for the variables, the data were analyzed with Little's MCAR test for missing data. The test showed that about 50 individual observations were missing across four variables, namely certifier age (1 missing observation), company age (2 missing observations), company revenue (21 missing values) and certifier revenue (30 missing values). These values were missing completely at random with $\chi_{(\mathrm{df}=19)}^{2}=10.617$, sig. $\mathrm{p}<0.936$. The missing data were substituted with the series mean rather than through linear interpolation due to the low level of missing data and to reduce the possibility of artificially strengthening the linear relationship of the variables (Hair et al., 2006).

A backwards stepwise method for estimating the logistic regression model was applied to the data with a final model emerging after twentyfive steps. The following firm characteristics were selected as the base comparison variables for the dummy variables; region of origin and industry sector. For the certifier, region of origin, and industry type: N. America (country of origin), N. America (country of origin), and Vegetable Producer (Industry Type) were used as the bases. For simplification purposes, the first step and the last step of the regression process have been reported in this paper. For further questions about the intermittent steps in the regression process, please contact the first author. Variables which were non-significant were eliminated until the model contained only variables which were statistically significant at $\alpha=0.05$. The final model correctly predicted $69.4 \%$ of the observed dependent variable values and contained four statistically significant independent variables: certifier age, certifier OTA membership, and companies from Africa or Europe.

Since logistic regression is based on probability and not on the ordinary-least-squares technique, it does not generate an $\mathrm{R}^{2}$ value for the measure of the variance explained by the model. Nagelkerke's $\mathrm{R}^{2}$ is one of the most widely-reported forms of measuring a pseudo- $\mathrm{R}^{2 \text {, the similar }}$ concept in logistic regression (Field, 2009). The model's pseudo- $\mathrm{R}^{2}$ had a value of 0.084 . 
The impact of the independent variables can be seen from Table 2. The $B$ value indicates the value of the coefficient. The value $\operatorname{Exp}(B)$ indicates the change in the odds ratio for the variable. The odds ratio is obtained by dividing the probability of an event occurring by the probability of an event not occurring. A value greater than 1 indicates that the event is more likely to occur, a value less than one indicates the opposite. The positive or negative sign for the value of $\mathrm{B}$ also indicates the probability of occurrence. If the coefficient is positive, the odds ratio will be greater than one, if negative, it is less than one.

In the case of the current study, the event of occurrence is the positive outcome was the positive result of having no offence or successfully winning an appeal and a negative outcome of being penalized with revocation or suspension of the license or a fine. This analysis did not indicate any significant influence of Organic Trade Association membership for the firm on the outcome. Therefore, no support was found for the first proposition.

The largest impact on the model came from the firm's country of origin. Countries which were established in Africa had a significant predictor $(\mathrm{p}<0.005)$ with a coefficient of -2.203 and an odds ratio of 0.110 . This means that companies from Africa were less likely to have a positive outcome in the court case compared to US firms. Companies with a certifier located in Europe were also statistically significant $(\mathrm{p}<0.005)$ with a coefficient of -0.681 and an odds ratio of 0.506 , indicating that such firms were less likely to have a positive outcome in the court case compared to firms with a certifier located in the US. The age of the certifier was also statistically significant $(\mathrm{p}<0.005)$ slightly negative with a coefficient of -0.007 and an odds ratio of 0.993 , indicating that companies with older certifiers were slightly less likely to have positive outcomes as compared to companies with younger certifiers.

Certifier OTA membership was the only statistically significant $(\mathrm{p}<0.005)$ positive predictor with a coefficient of 0.651 and an odds ratio of 1.918 indicating that if the certifying agency was OTA certified, the 
company had better odds for having a positive legal result. This result provides support for the second proposition.

\section{Discussion}

The lack of support for the first proposition indicates that the trade association membership does not directly deflect disruptions for member firms in this dataset. However, the lack of significance may be because only 112 of the 879 firms belonged to the Organic Trade Association (OTA). This characteristic of the population may lead one to tentatively conclude that OTA members are less likely to face sanctions because the professional association is exercising its traditional gatekeeping role of professional associations by denying membership to firms that do not exhibit legitimate characteristics (Lane \& Bachmann, 1997; Marchington \& Vincent, 2004; Ruef \& Scott, 1998). Indeed, such an interpretation would lend credence to Barley's assertion that the "protection of legitimacy may be built into the structure of the field itself" (2010, p. 796). Future research may seek to determine if members of a professional association will be more likely to avoid legitimacy challenges than non-member organizations. In fact, the avoidance of potential disruptions to their activities may be the preferred response to institutional forces, since it requires relatively minimal effort (Oliver, 1997)

While the influence of the OTA may not be evident in the membership status of the offending firm, the results show that the certifiers' status was significantly related to the outcome of the appeal. Thus, support for the second proposition was found and suggests that the certifiers serve as a buffering device for the OTA by deflecting negative outcomes for existing members through the deployment of the OTA's legitimacy. Although certifiers can exert coercive isomorphic pressures, the results indicate they may also be able to buffer potential legitimacy challenges by providing legitimacy that non-member firms lack. Thus, if the legal proceedings metaphor advanced earlier was extended, one could argue that the certifying agencies are serving as effective council; implicitly bargaining 
the sentence down to a more manageable outcome. Conversely, these findings could be interpreted from the perspective of the non-member certifier. Without access to the influence of the OTA, these certifiers may have to take greater risks by certifying more suspect firms in order to generate sufficient revenue to sustain operations.

Lastly, it is important to call attention to the liability of foreignness that is apparent in the findings for both target and certifying firms. This result could point to a lack of familiarity with the United States legal system as well as a diminished level of embeddedness in the organic food network. Future research may wish to further explore the country of origin effect.

\section{Contributions}

This study makes both theoretical and practical contributions. First, this study advances the literature on the role of professional associations in exerting institutional pressures. Although scholars have maintained that professional associations act as "agents of reproduction" (Greenwood et al., 2002), few studies have directly measured the strategies professional associations deploy to maintain prevailing institutional logic. This study represents perhaps one of the first efforts towards this end. The study provides additional insight into institutional maintenance process by calling attention to deflection, a new strategy of institutional maintenance, which may be considered to be a special form of buffering that occurs after the firm is subjected to a legitimacy challenge. Finally, by considering the influence of the certifying agencies, an additional dynamic into institutional work analyses has been proposed. As such, the study may provide an opportunity to further integrate social network theory into institutional studies (Rowley, 1997).

The study also makes two contributions for practitioners. For firms seeking certification, the results of this study highlight the importance of the membership status of the certifying agency. Firms looking to enter into the United States organic food industry would benefit from seeking 
certifiers based in the US with an active OTA membership. Additionally for certifiers, these findings suggest the value of professional association membership when a client faces sanctions.

\section{Limitations AND FUtURE RESEARCH}

The study had a number of limitations that restrict the generalizability of the findings and may not capture the entire range of dynamics present in the processes. First, the study only considered the events occurring in the US organic food industry. While such a boundary may have eliminated the potential for co-founding variables, it is uncertain if these trends may be observable in other industries or countries. Future research may explore the influence of trade association membership in other contexts in which deflection may occur. One potentially interesting extension may be the lumber industry, since the growth in the popularity of environmentally-responsible certifications.

Another limitation to the study was that the use of archival data necessitated the assumption that current Organic Trade Association membership denoted membership at the time of the sanction. However, because the period of analysis was six years, this assumption seems to have had little impact on the results.

Further limiting the generalizability of these findings may have been that only the process of maintenance through the protection of membership was considered. Because various types of institutional work occur simultaneously (Empson et al., 2013), future research may wish to consider the manner in which trade associations create and disrupt institutions as well. Furthermore, this analysis did not consider the microprocesses of institutionalization (Lawrence et al., 2011), such as lobbying efforts or congressional testimonies of the OTA members. An avenue for future research may be able to examine the specific activities of trade association's representatives. 
Finally, this study analyzed an unusual circumstance in which the charge and the sentencing occur separately. The structure of legitimacy decisions is normally more compressed; with the sanction and decision occur almost simultaneously, and thus the ability to observe deflection tactics may be more elusive in other contexts. Future research may seek other situations similar to the empirical context found here to explore questions such as the influence of more powerful trade associations such as the United States Chamber of Commerce. Various appellant courts and plea-bargaining or negotiation proceedings offer other promising venues for researchers. Analyzing instances of compromise represents another intriguing avenue for future research. If firms cannot successfully deflect a disruption, they may seek to compromise (Oliver, 1991).

\section{REFERENCES}

Ashforth, B. E., \& Gibbs, B. W. (1990). The double-edge of organizational legitimation. Organization Science, 1(2), 177-194. doi:http:// dx.doi.org/10.1287/orsc.1.2.177

Barley, S. R. (2010). Building an institutional field to corral a government: A case to set an agenda for organization studies. Organization Studies, 31(6), 777-805. doi:http://dx.doi.org/10.1177/0170840610372572

Clemens, B. W., \& Douglas, T. J. (2005). Understanding strategic responses to institutional pressures. Journal of Business Research, 58(9), 1205-1213. doi:http://dx.doi.org/10.1016/j.jbusres.2004.04.002

Currie, G., Lockett, A., Finn, R., Martin, G., \& Waring, J. (2012). Institutional work to maintain professional power: recreating the model of medical professionalism. Organization Studies, 33(7), 937-962. doi:http:// dx.doi.org/10.1177/0170840612445116

DiMaggio, P. J., \& Powell, W. W. (1983). The iron cage revisited: Institutional isomorphism and collective rationality in organizational fields. American Sociological Review, 147-160. doi:http:// dx.doi.org/10.2307/2095101 
Empson, L., Cleaver, I., \& Allen, J. (2013). Managing partners and management professionals: institutional work dyads in professional partnerships. Journal of Management Studies, 50(5), 808-844. doi:http:// dx.doi.org/10.1111/joms.12025

Field, A. (2009). Discovering statistics using SPSS. Beverly Hills: Sage Publications.

Giddens, A. (1984). The constitution of society: Outline of the theory of structuration. Berkley: University of California Press.

Goodstein, J. D. (1994). Institutional pressures and strategic responsiveness: Employer involvement in work-family issues. Academy of Management Journal, 37(2), 350-382. doi:http:// dx.doi.org/10.2307/256833

Granovetter, M. (1985). Economic action and social structure: the problem of embeddedness. American journal of sociology, 481-510. doi:http:// dx.doi.org/10.1086/228311

Greenwood, R., Hinings, C., \& Suddaby, R. (2002). Theorizing change: The role of professional associations in the transformation of institutionalized fields. Academy of Management Journal, 45(1), 58-80. doi:http://dx.doi.org/10.2307/3069285

Hair, J. F., Black, W., Babin, B., Anderson, R. E., \& Tatham, R. L. (2006). Multivariate data analysis (6th ed.). Upper Saddle River, NJ: Pearson Education.

Hamel, G., Doz, Y. L., \& Prahalad, C. K. (1989). Collaborate with your competitors and win. Harvard Business Review, 67(1), 133-139.

Hannan, M. T., \& Freeman, J. (1984). Structural inertia and organizational change. American Sociological Review, 149-164. doi:http:// dx.doi.org/10.2307/2095567

Hirsch, P. M., \& Bermiss, Y. S. (2009). Institutional “dirty” work: preserving institutions through strategic decoupling. In T. B. Lawrence, R. Suddaby, \& B. Leca (Eds.), Institutional work: Actors and agency in institutional studies of organizations (pp. 262). New York: Cambridge University Press. 
Hosmer Jr, D. W., \& Lemeshow, S. (1989). Applied logistic regression. New York: John Wiley \& Sons.

Ingram, M., \& Ingram, H. (2005). Creating credible edibles: The organic agriculture movement and the emergence of US federal organic standards. In D. S. Meyer, V. Jenness, \& H. Ingram (Eds.), Routing the Opposition: Social movements, Public Policy, and Democracy. Minneapolis, MN: University of Minnesota Press.

King, A. A., \& Lenox, M. J. (2000). Industry self-regulation without sanctions: the chemical industry's responsible care program. Academy of Management Journal, 43(4), 698-716. doi:http:// dx.doi.org/10.2307/1556362

Lane, C., \& Bachmann, R. (1997). Co-operation in inter-firm relations in Britain and Germany: the role of social institutions. British Journal of Sociology, 226-254. doi:http://dx.doi.org/10.2307/591750

Lawrence, T., \& Suddaby, R. (2006). Institutions and institutional work. In S. Clegg, C. Hardy, T. Lawrence, \& W. Nord (Eds.), The Sage handbook of organization studies (2nd ed.). Thousand Oaks, CA: Sage.

Lawrence, T., Suddaby, R., \& Leca, B. (2011). Institutional work: Refocusing institutional studies of organization. Journal of Management Inquiry, 20(1), 52-58. doi:http://dx.doi.org/10.1177/1056492610387222

March, J. G., Olsen, J. P., \& Christensen, S. (1976). Ambiguity and choice in organizations. New York: Oxford University Press.

Marchington, M., \& Vincent, S. (2004). Analysing the influence of institutional, organizational and interpersonal forces in shaping inter-organizational relations. Journal of Management Studies, 41(6), 1029-1056. doi:http://dx.doi.org/10.1111/j.1467-6486.2004.00465.x

Meyer, J. W., \& Rowan, B. (1977). Institutional organizations: Formal structure as myth and ceremony. American journal of sociology, 83(2), 340-363. doi:http://dx.doi.org/10.1086/226550

Meyer, J. W., \& Scott, W. R. (1983). Centralization and the legitimacy problems of local government Organizational environments: Ritual and rationality (pp. 199-215). Beverly Hills, CA: SAGE. 
Oliver, C. (1991). Strategic responses to institutional processes. Academy of Management Review, 16(1), 145-179. doi:http://dx.doi.org/10.5465/ AMR.1991.4279002

Oliver, C. (1997). The influence of institutional and task environment relationships on organizational performance: the Canadian construction industry. Journal of Management Studies, 34(1), 99-124.

Rowley, T. J. (1997). Moving beyond Dyadic Ties: A Network Theory of Stakeholder Influences. The Academy of Management Review, 22(4), 887-910. doi: $10.2307 / 259248$

Ruef, M., \& Scott, W. R. (1998). A multidimensional model of organizational legitimacy: Hospital survival in changing institutional environments. Administrative science quarterly, 877-904. doi:http:// dx.doi.org/10.2307/2393619

Scott, W. R. (2014). Institutions and organizations: Ideas, interests, and identities (4th ed.). Los Angelos, CA: Sage.

Suddaby, R., \& Viale, T. (2011). Professionals and field-level change: Institutional work and the professional project. Current Sociology, 59(4), 423-442. doi:http://dx.doi.org/10.1177/0011392111402586

Thompson, J. D. (2008). Organizations in action: Social science bases of administrative theory (6th ed.). New Brunswick, NJ: Transaction Publishers.

Trank, C. Q., \& Washington, M. (2009). Maintaining an institution in a contested organizational field: the work of the AACSB and its constituents. In T. Lawrence, R. Suddaby, \& B. Leca (Eds.), Institutional work: Actors and agency in institutional studies of organizations (pp. 236): Cambridge University Press.

Tucker, A. (2008). Trade associations as industry reputation agents: a model of reputational trust. Business and Politics, 10(1). doi:http:// dx.doi.org/10.2202/1469-3569.1218

Weick, K. E. (1976). Educational organizations as loosely coupled systems. Administrative science quarterly, 21(1), 1-19. doi:http:// dx.doi.org/10.2307/2391875

Zald, M. N., \& Lounsbury, M. (2010). The wizards of Oz: Towards an institutional approach to elites, expertise and 
command posts. Organization Studies, 31(7), 963-996. doi:http:// dx.doi.org/10.1177/0170840610373201

Zucker, L. G. (1988). Where do institutional patterns come from? Organizations as actors in social systems. In L. G. Zucker (Ed.), Institutional patterns and organizations: Culture and environment (pp. 23-52).

\section{Citation Information}

Sheridan, Michael J., Michael Hartmann, and Erik Jonisz. "Professional Associations and Deflection Tactics: A Theory and Exploratory Analysis." The BRC Academy fournal of Business 7, no. 1 (2017): 23-43. http:// dx.doi.org/10.15239/j.brcacadjb.2017.07.01.ja02

\section{Web Appendix}

A web appendix for this paper is available at:

http://dx.doi.org/10.15239/j.brcacadjb.2017.07.01.wa02 